\title{
MEMORY ASSESSMENT CLINICS: PROCESS AND MANAGEMENT
}

\author{
Y Shukla, Staff Grade, Psychiatry \\ Oaklands Unit, Lancaster
}

\section{INTRODUCTION}

Dementia is an organic mental disorder due to disease of the brain, chronic or progressive in nature. Its characteristics are:

- loss of memory (initially short term and then long term)

- disturbance of multi higher cortical function: orientation, comprehension, learning capacity, thinking, intellect, judgement, language; dysphasia, apraxia (inability to perform learned movement when there is no sensory or motor deficit)

- agnosia (inability to understand or recognise objects and form in presence of normal peripheral sensation) in a clear consciousness.

There is also deterioration in emotional control, social behaviour, motivation, activities of daily living ie washing, dressing and personal care, causing difficulties in maintaining an independent life style and causing a profound effect on carers. The patient's disability places a burden on the carer and affects the patient's and care giver's quality of life.

This article focuses on memory clinics within Morecambe Bay Primary Care Trust: it outlines operational policies, structure, assessment process, investigations and diagnosis, basic information regarding anti-dementia drugs and other management of all patients referred to the memory clinic giving guidance, education and information regarding support services to patients and carers.

Memory clinics were first set up in United States in the mid-1970s. They provided diagnosis, treatment and advice for people with memory impairment and support to their families. These clinics were introduced to the United Kingdom in 1983. They are a specialist service offering assessment and early diagnosis of dementia. They have steadily increased in numbers and their functions.

We have four memory assessment clinics within Morecambe Bay Primary Care Trust, based at Oaklands Day Hospital (Lancaster area), Moss View Day Hospital (Heysham area), Kirkstone Day Hospital (Kendal) and a day clinic is planned for the Barrow area.

These clinics aim to provide a comprehensive assessment of memory impairment for the early detection and diagnosis of dementia. This involves a multidisciplinary assessment using research-based tools. Where appropriate, anti-dementia drugs (anticholinesterase inhibitors) will be prescribed for Alzheimer's disease as per NICE guidelines, and psychosocial support and education will be offered to both the patient and carer. This service will be offered to any person living in the Bay Community Primary Trust catchment area.

The service offered by the team is accessible, flexible and adaptable and will comprise a full and proper assessment of the individual's needs, taking into consideration carers' opinions and needs. The aim is to improve and maintain the person's independence and to support people so that they can continue to live in their own home. The team is committed to maintaining the highest possible standard of care consistent with available resources, to ongoing evaluation and the implementation of services offered in a close network with other primary care workers.

The multi-disciplinary team consists of psychiatrists, nurses, psychologists, occupational therapists, administrative staff and voluntary organisations ${ }^{(1)}$.

The consultant psychiatrist will have overall medical responsibility for people accepted by the clinic. Medical support is also provided by a staff grade doctor for older people with mental health problems.

Neuropsychologist All patients under the age of 65 will be seen by a neuropsychologist. Patients with sensory deficits and complex cases where diagnosis is unclear will also be referred to a neuropsychologist where appropriate.

Occupational therapist (OT) The OT's role is to contribute to the process of assessment and facilitation of diagnosis in more complex cases.

Administrative staff They provide and maintain clinical information regarding patients and appointments.

Team coordinator The registered mental health nurse in charge of the day hospital will manage the team and coordinate the use of resources within the team to maximise effective interventions.

Care support worker Under the direction of the team coordinator the care support worker will provide the handson care, supporting the older person and the carer.

The clinic takes place one day a week at each unit from $9 \mathrm{am}$ to $5 \mathrm{pm}$. Contact can be made at any time during normal working hours by phoning the respective day hospital.

\section{REFERRAL PROCESS}

A new referral will be accepted from both primary and secondary care sources. The patient's family doctor needs to authorise the referral if it is made by any other member of the primary care team. All referrals will be received by the team; if the team feels a multi-disciplinary assessment is needed then: -

a) one of the team members will be appointed as the care coordinator for the patient while he/she receives care in the clinic 
b) the care coordinator will liaise with the patient's GP and any other agencies involved in the patient's care where appropriate.

Referrals to the clinic must be accompanied with as much information as is available.

We appreciate the following points being mentioned in the referral letter:

1. Present problem and duration. How it affects the individual/family

\section{Present medication}

3. Family history of dementia

4. Past medical history including cardiovascular disease, head injury, epilepsy, gastric ulcers, chronic obstructive airways disease, multiple sclerosis etc as well as other relevant medical illnesses

5. History of alcohol intake (amount and duration)/substance abuse

\section{Patient's occupation ie retired boxer, footballer etc}

7. Spouse/carer's health and their input

\section{Any support to patient/carer}

We would also like to have the following investigations carried out prior to referral to a memory clinic:

full blood count

profile

thyroid function test

serum B12 and folate

blood glucose

ECG

Referrals which do not fulfil the memory assessment clinic criteria will be redirected to the appropriate agency and the referrer informed of this.

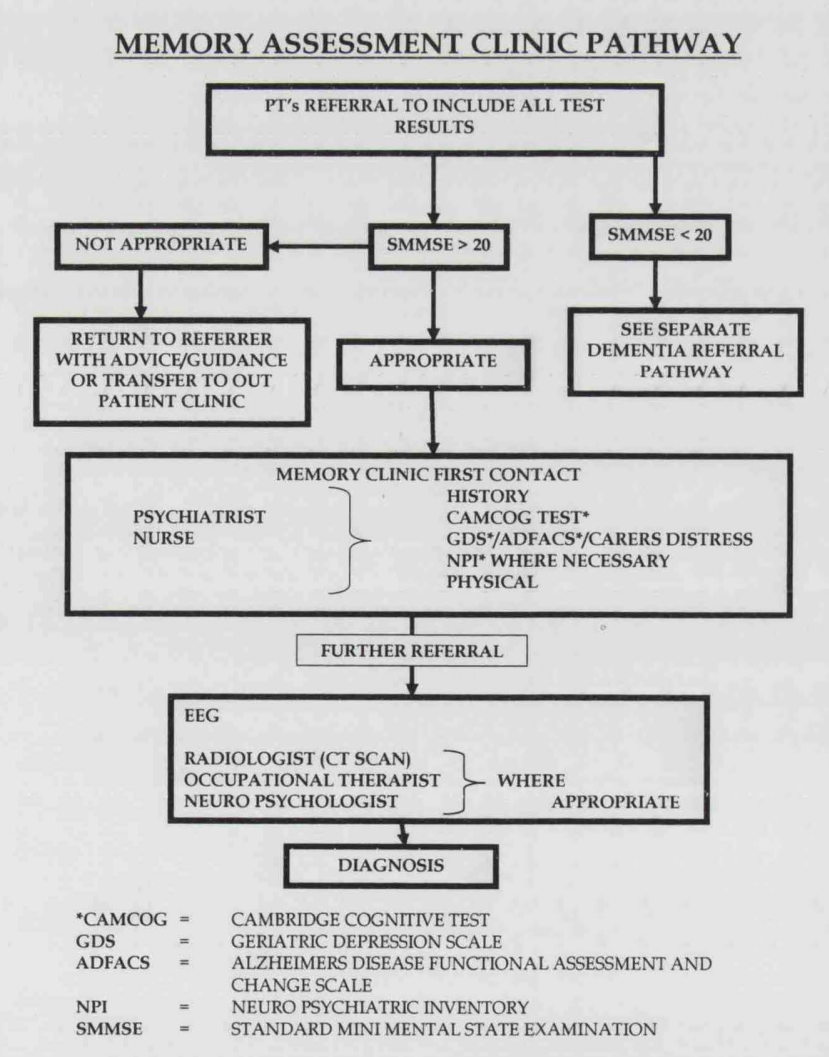

Referral criteria

1. The person must reside with Morecambe Bay Primary Care Trust area

2. He/she must have reported a history of memory impairment

3. There is no age restriction to access to this service; the service is based on clinical need only

4. The person must score between $20-30$ on mini mental state examination

\section{Assessment}

Before assessment starts a designated member will give clear details of the assessment process. The team members will attempt to find out if patient and/or carer wishes to be informed of the assessment outcome and diagnosis. This information will be recorded in the patient's file.

The initial process of assessment will be carried out by a psychiatrist and a qualified nurse. The assessment is a noninvasive intervention and is mainly conducted through interviews and questioning, using research-based tools and rating scales. The whole process should last between one and a half hours and two hours and is described in detail below.

Further referrals to other disciplines ie occupational therapy, neuropsychology, EEG and radiology (re scan) would be made where appropriate. Appendix 1 gives the criteria for requesting a scan, and appendix 2 and 3 show a flow chart regarding the memory assessment clinic pathway and diagnosis.

\section{Diagnosis}

A diagnosis of cognitive impairment is the first step forward in understanding and towards care. The diagnosis carries information about the condition, the outlook and possible treatment. It is the patient's right to be informed of the

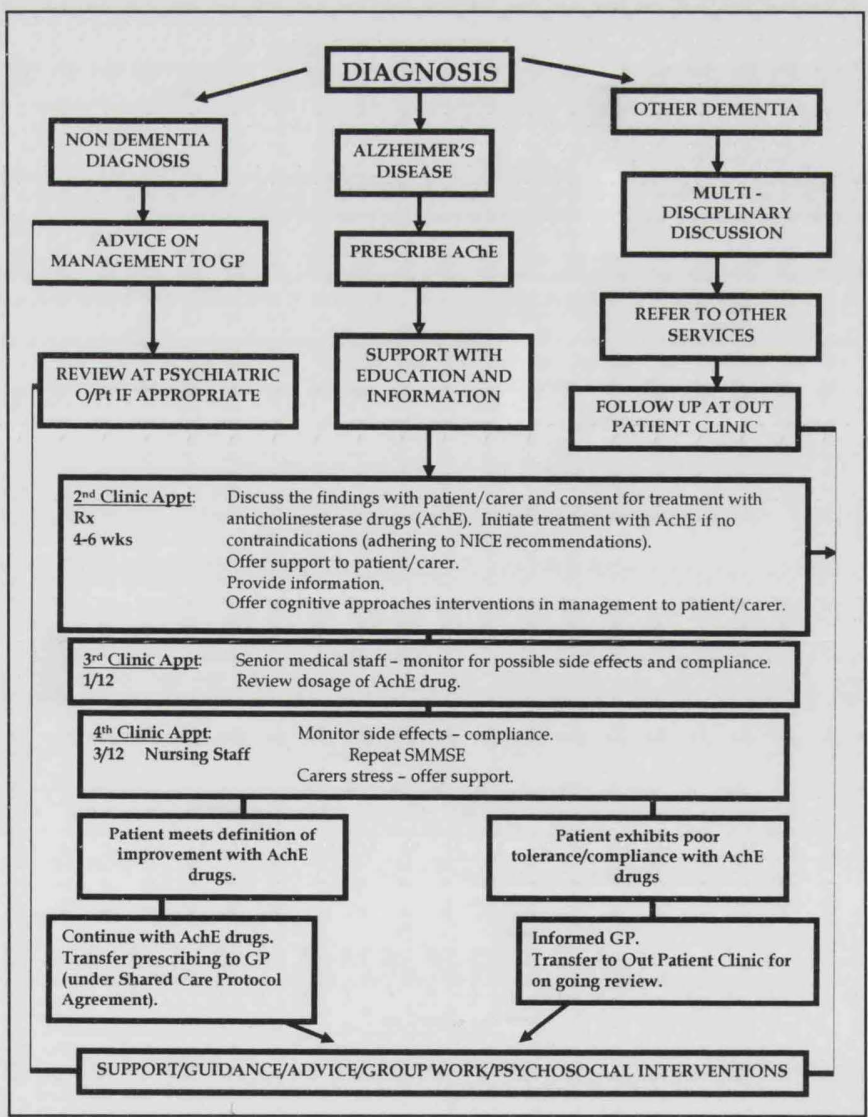


diagnosis and we respect every referred patient's wishes should they choose otherwise. Where appropriate the disclosure of the assessment outcome and diagnosis will be delayed if this deemed more damaging to the patient and carer.

\section{Discharge from the clinic}

Discharges will only take place following a multi-disciplinary review and with reference to the agreed care plan. Discharge will take place upon any of the following: -

a) the patient's mental health becomes more complex and transfer to mainstream mental health services is deemed more appropriate

b) the patient/carer no longer feels the need for the team's intervention

c) no definite evidence of dementia or other form of mental ill health is found

d) the patient moves permanently from the trust's catchment area

The patient's family doctor and other disciplines involved in the individual's care will be notified upon discharge from the clinic.

\section{Assessment process}

This is done in two parts; a doctor interviews the relative/informant while the senior nurse does cognitive test scoring.

\section{Criteria For CT Scan}

1) age less than 60 years

2) rapid (e.g. 1 to 2 months) unexplained decline in cognition or function

3) "short" duration of dementia ( $<1 \mathrm{yr}$ in patients $<70)$

4) recent and significant head trauma

5) unexplained neurologic symptoms (e.g. new onset of severe headache or seizures)

6) history of cancer (especially in sites and types that metastasize to the brain)

7) use of anticoagulants or history of bleeding disorder

8) history of urinary incontinence and gait disorder early in the course of dementia (as may be found in normal pressure hydrocephalus)

9) any new localizing sign (e.g. hemiparesis or a Babinski reflex)

10) unusual or atypical cognitive symptoms or presentation (e.g. progressive aphasia or frontal lobe syndrome)

11) gait disturbance

12) EEG shows evidence of localized pathology or marked asymmetry

13) evidence of gross cerebro vascular disease would alter the management of the case

\section{Figure 1}

\section{Interview with relative/informant}

$>$ onset of symptoms and progress

> everyday competence

- forgetful/losing things/misplacing things - accusations/ shopping list/ability to recall recent events/dwell in past

- orientation - mixed up in time/day/place/finding way about inside and outside

- communication skills/word-finding difficulty/losing thread of conversation
- ability to use household appliances eg cooker, microwave, washing machine, telephone, TV, VCR

> change in personality/behaviour/cognition

$>$ loss of interest/depression/paranoid symptoms

> biological functions - appetite/bowels/sleep - any disturbance

capability to manage driving

$>$ finance/enduring power of attorney

family history of cognitive decline

\section{Interview with subject}

If the subject fails to provide satisfactory answers to two out of three questions (name, date of birth, age) then the interviewer may proceed to cognitive examination. Otherwise, the subject's present mental state should be observed, particularly identifying symptoms relating to depression/paranoid psychosis.

Enquiries regarding past history and family history are also made to establish the speculative risk for Alzheimer's disease.

Physical examination

- defect of hearing/sight

- pulse/BP

- systematic examination - note positive findings

- include CNS

Investigations

- blood results

- EEG

- Scan (CT/MRI) if indicated (see Appendix 1)

- ECG

\section{Cognitive examination}

Tests depend on

- the understanding of a language

- educational attainment

- cultural background

- impairment of hearing or vision

Several tests are used in assessment. The main tests used in clinics are given below.

I will briefly mention what they assess and their limitations.

\section{Cognitive tests - interpretation}

\section{SMMSE}

Items comprising the Mini Mental State Examination (MMSE) of Folstein et al (1975). It consists of 19 items and the maximum score is 30 . This test focuses mainly on memory orientation, concentration, praxis, language, writing and sensory recognition (gnosis).

Interpretation score 26-29 mild cognitive impairment score $20-26 \mathrm{mild} /$ moderate cognitive impairment score 15-20 moderate cognitive impairment score $8-15$ moderate/severe cognitive impairment score 8 severe cognitive impairment.

\section{2. $\mathrm{CAMCOG}^{(3)}$}

Cambridge Cognitive Examination (CAMCOG-R) and subscales. CAMCOG is more detailed and covers 
cognitive functions such as attention, memory, orientation, praxis, gnosis, language, abstraction and calculation. CAMCOG is good at identifying/confirming early cognitive impairment. It is sensitive to different cognitive problems and abilities, and copes well with the ceiling effect (ie for brighter people). It has a high level of test reliability.

The total score is 105; the cut-off point for dementia is $80 / 81$. The remote memory items are from the original cardex and are intended for subjects born before 1940. For subjects born after 1940 the corresponding questions are revised accordingly.

\section{Assessment of executive function}

One is verbal (ideational fluency), the other non-verbal (visual reasoning).

a abstract thinking (eg similarity between apple and banana, or plant and animal)

b ideational fluency (eg give different uses for a bottle)

c visual reasoning (demonstrated by use of booklet used as a diagnostic tool)

\section{Alzheimer's Disease Functional Assessment and} Change Scale (ADFACS) ${ }^{(4)}$

Used on the first visit, this test gives a baseline idea of the functional ability of the individual and the carer's view about it. This will cover both instrumental and basic activities of daily living. The scale is divided into two sections:

Part A deals with instrumental activities of daily living

Part B deals with basic activities of daily living (feeding, toileting and dressing).

Each item is scaled from 0-4.

Interpretation score 1-16 mild impairment score 17-32 moderate impairment score 33-48 moderate to severe impairment score 49-64 severe impairment.

\section{GDS Assessment ${ }^{(5)}$}

This questionnaire highlights the subjective depressive

symptoms. There are 15 questions, each of which scores one point. The lower the score, the fewer the depressive symptoms.

Depression in the elderly is very common, and can also present as a pseudodementia.

Depression can be a side-effect of medication eg cerebrovascular drugs, steroids, hormones, non-steroid antiinflammatory drugs and benzodiazepine.

Life events such as loss of health, money, home, expectations, social status or social life can also aggravate depressive symptoms.

The following symptoms are common with dementia and depression: -

1. Cognitive problems

2. Loss of energy

3. Social withdrawal

4. Neglecting oneself

5. Slowness of movement

6. Agitation

Symptoms differ in depression and in dementia: -

\section{Dementia}

may answer question in ways that are difficult to understand

might have difficulty with common occasions eg finding right words

usually have problems with remembering things

likely to have difficulties with remembering things that have happened recently

might have problems with written and numerical functions might have difficulty with abstract form

\section{Depression}

no long history of memory loss and disorientation

often irritable

can usually orientate themselves in terms of time, place and person

might refuse to answer

\section{Cognitive function \\ Orientation}

Language

memory

attention/

calculation

Praxis

abstract thinking

Perception

\section{Brief description of item}

day+date+month+year+season+county+town +streets+floor+place

comprehension

nod+touch+ceiling+tap

+hotel+village+radio

+read1+read2

expression

hammer+chemist+bridge+opinion

+ name objects+animals+ifs+address =

Remote-

Recent-

Learning-

first world war+second world war

+German+Russia+Mae+flyer

queen+heir+prime minister+news

recall pictures+recognise pictures

+recall address

count backwards+serial sevens

+calculation $1+$ calculation 2

pentagon+spiral+house+clock

+envelope+wave+cut+teeth

similarities $1+$ similarities 2

similarities 3+similarities 4

faces+views+recognise person

\section{Maximum score}

10 


\section{Ischaemic score re vascular dementia ${ }^{(6)}$}

\begin{tabular}{|l|l|c|}
\hline & & Score \\
\hline A & Abrupt onset & 2 \\
\hline B & Stepwise deterioration & 1 \\
\hline C & Fluctuating course & 2 \\
\hline D & Nocturnal confusion & 1 \\
\hline E & Relative preservation of personality & 1 \\
\hline F & Depression & 1 \\
\hline G & Somatic complaints & 1 \\
\hline H & Emotional incontinence & 1 \\
\hline I & History of hypertension & 1 \\
\hline J & History of strokes & 2 \\
\hline K & Evidence of associated atherosclerosis & 1 \\
\hline L & Focal neurological symptoms & 2 \\
\hline M & Focal neurological signs & 2 \\
\hline
\end{tabular}

Interpretation - score recommended by Hachinski are: 0-4 no vascular dementia

$7+$ vascular dementia.

In order to make a diagnosis of Alzheimer-type dementia, the practitioner needs to take a full history and examination together with an assessment of the cognitive deficits causing memory impairment (impaired ability to learn new information or to recall previously learnt information), and one or more of the following cognitive disturbances:

- aphasia (language disfunction)

- apraxia (impaired ability to carry out motor activities despite intact motor function)

- agnosia (failure to recognise or identified objects despite intact sensory function)

- disturbance in executive functions (planning, organising, sequencing, abstracting)

- cognitive deficits cause significant impairment in social or occupational functioning and represent a significant decline from a previous level of functioning

- the cause is characterised by gradual onset and continuing cognitive decline

- cognitive deficits are not due to any other central nervous system or systemic conditions or substance induced conditions

- disturbance not accounted for by major depressive disorder or schizophrenia

Alzheimer's disease patients scoring above 12 on mini mental state examination are prescribed anti-dementia drugs as per NICE guidelines.

\section{Cognitive enhancer drugs - Donepezil, Rivastigmine, Galantamine}

These drugs may have a positive effect and temporarily slow down the progression of symptoms in people in the early to middle stage of the disease. They can reduce anxiety, improve mood and restore confidence.

There is a newer drug, Mememtine (Abixa) that has recently been licensed in the United Kingdom. The drug company has suggested their role in treatment of moderate to severe to severe Alzheimer's disease. It has been used for the last 10 years in Germany.

\section{SUMMARY}

The aim of primary care management of patients with dementia is to improve their quality of life and optimise the functional performance by enhancing cognition, behaviour and motor functions.

About $16 \%$ ( 8 million) of the United Kingdom's population are about 65 years old and approximately 700,000 people suffer from dementia including 17,000 pre-senile dementia $^{(7)}$. Alzheimer's disease accounts for $55 \%$ of dementia followed by vascular dementia (about 15\%), mixed dementia (about 6\%), dementia with Lewy bodies (10\%), fronto-temporal dementia (4\%) and others about $10 \%$.

\begin{tabular}{|lcccc|}
\hline & $\mathbf{6 5 - 6 9}$ years & $\mathbf{7 0 - 7 9}$ years & $\mathbf{8 0 - 8 4}$ years & $\mathbf{8 5 +}$ \\
\hline Male & 2972 & 4659 & 1257 & 857 \\
\hline Female & 3404 & 6137 & 2186 & 2396 \\
\hline
\end{tabular}

Elderly population in Lancaster District from census 2001

The prevelance of dementia in the age group $65-85$ is $5 \%$ and above 85 years is $20 \%$. This would mean that the likely number of cases in the Lancaster area is over 2,000 cases.

There is a need for very early diagnosis of Alzheimer's disease. Cognitive decline in the elderly is mainly due to Alzheimer's disease, vascular and other dementia and can be confounded by depression, age, education level and morbid IQ. As the elderly population increases so does the burden of care for those with dementia.

Acknowledgment: I am grateful to Lindsay Wren for her secretarial support for this article.

\section{REFERENCES}

1 Morecambe Bay Primary Care Trust policy document

2 SMMSE - Standardised Mini Mental State Examination of Folstein 1975

3 CAMDEX-R - The Cambridge examination for mental disorders of the elderly-revised

4 Galasko D, Bennett D, Sano M et al. Alzheimer's Disease Functional Assessment and Change Scale (ADFACS). Alzheimer's Dis and Assoc Disorders 1997;11(supp 2):S3339

5 Yesavage JA, Brink TL, lum O, Huang V, Adey M, Leirer O. Development and validation of a geriatric depression screening scale: a preliminary report. J Psychiatr Res $1983 ; 17: 37-49$

6 Gregory RJ, Swanwick et al. Discriminating power of the Hachinski ischaemic score in a geriatric population with mild dementia. Int J Geri Pscyh 1995;10(8):679-85

7 Information available from Alzheimers Disease Society

\section{RECOMMENDED READING}

National Service Framework: Mental Health of Older People 


\begin{tabular}{|c|c|c|c|c|}
\hline Cognitive Assessment & $\begin{array}{l}\text { Functional Assessment } \\
\text { (ADFACS) }\end{array}$ & $\begin{array}{l}\text { Neuropsychiatric } \\
\text { Symptoms }\end{array}$ & Behavioural Functions & Personality \\
\hline $\begin{array}{l}\text { AMNESIA } \\
\text { Short term memory loss } \\
\text { Long term memory loss }\end{array}$ & $\begin{array}{l}\text { INSTRUMENTAL } \\
\text { ACTIVITIES } \\
\text { Use of objects is lost first }\end{array}$ & $\begin{array}{l}\text { MOOD } \\
\text { Depression, psychomotor } \\
\text { retardation. apathy, loss } \\
\text { of interest, poor appetite, } \\
\text { disturbed sleep } \\
\left.\begin{array}{l}\text { Elation/ } \\
\text { disinhibition/ } \\
\text { Hypomania }\end{array}\right\} \begin{array}{l}\text { relatively } \\
\text { infrequent }\end{array} \\
\end{array}$ & $\begin{array}{l}\text { Wandering } \\
\text { (topographical confusion) } \\
\text { Change in eating habit } \\
\text { Altered sleep pattern } \\
\text { Increased confusion } \\
\text { in evenings }\end{array}$ & $\begin{array}{l}\text { Acceleration of } \\
\text { personality traits } \\
\text { Change in personality: } \\
\text { argumentative/stubborn/ } \\
\text { aggressive } \\
\text { Inappropriate sexual } \\
\text { behaviour }\end{array}$ \\
\hline $\begin{array}{l}\text { APHASIA } \\
\text { nominal aphasia } \\
\text { repetitions } \\
\text { syntax affected } \\
\text { comprehension of speech } \\
\text { affected } \\
\text { speech decrease } \\
\text { preservation } \\
\text { echolalia } \\
\text { abnormal non-speech } \\
\text { utterance }\end{array}$ & \begin{tabular}{|l} 
SELF-CARE \\
Dressing \\
Personal hygience
\end{tabular} & $\begin{array}{l}\text { PSYCHOSIS } \\
\text { hallucinations (visual } \\
\text { hallucinations - more } \\
\text { commonly, Lewy Body } \\
\text { Dementia) } \\
\text { Paranoid symptoms }\end{array}$ & & \\
\hline $\begin{array}{l}\text { AGNOSIA } \\
\text { Difficulty in recognising } \\
\text { and naming objects } \\
\text { Implications for care needs } \\
\text { and safety if unrecognised } \\
\text { objects are important for } \\
\text { daily living }\end{array}$ & & & & \\
\hline $\begin{array}{l}\text { APRAXIA } \\
\text { Results in difficulties with } \\
\text { dressing, kitchen tasks etc }\end{array}$ & & & & \\
\hline $\begin{array}{l}\text { VISUOSPATIAL } \\
\text { DIFFICULTIES } \\
\text { Results in topographic } \\
\text { disorientation/wandering/ } \\
\text { becoming lost }\end{array}$ & & & & \\
\hline $\begin{array}{l}\text { ATTENTION/ } \\
\text { CONCENTRATION } \\
\text { Results in inability to remain } \\
\text { in meaningful task }\end{array}$ & & & & \\
\hline $\begin{array}{l}\text { ABSTRACT } \\
\text { THINKING/JUDGEMENT } \\
\text { May result in problems such } \\
\text { as miscalculating } \\
\text { situation/finance planning }\end{array}$ & & & & \\
\hline
\end{tabular}

Clinical points of assessment process 